\title{
Evidence that the seasonal antler cycle of adult Reeves' muntjac (Muntiacus reevesi) is not associated with reproductive quiescence
}

\author{
Norma G. Chapman ${ }^{1}$ and Stephen Harris ${ }^{2 *}$ \\ ${ }^{1}$ Larkmead, Barton Mills, Bury St Edmunds, Suffolk IP28 6AA, UK; and ${ }^{2}$ Department of Zoology, \\ University of Bristol, Woodland Road, Bristol BS8 IUG, UK
}

\begin{abstract}
Summary. Data were obtained from post-mortem investigations of 190 culled and road-killed muntjac bucks between 1967 and 1989. Although adult bucks (i.e. those having undergone at least one antler cycle) have a synchronous annual antler cycle, unlike temperate-zone cervids there was little seasonal variation in testis size or activity, or in the size and activity of the epididymidis or accessory reproductive glands. Spermatogenesis was not abated when the antlers were in velvet and year-round fertility was achieved without additional sperm storage. There was little seasonal change in plasma testosterone concentrations in samples obtained from captive and free-living bucks although castration caused antler casting and prevented mineralization. Hence the data are equivocal as to the role of steroids in driving the antler cycle; experimental work on this species would be valuable in examining the mechanisms which regulate the antler cycle.
\end{abstract}

Kewords: Muntjac deer; reproduction; testis; accessory glands; antler cycle; fertility

\section{Introduction}

There are $\sim 40$ species of deer distributed widely throughout the tropical, temperate and arctic regions of the world (Whitehead, 1972). In most temperate-zone species, there is marked reproductive synchrony among females, but reproductive activity may occur throughout the year in tropical species, although most exhibit a peak period of births (Zuckerman, 1953; Lincoln, 1985). Similarly, males of temperate-zone species have a synchronized antler cycle that is a reliable indicator of their seasonal testicular status (Bubenik, 1986). Lincoln (1984) has summarized the mechanism involved in the control of antler growth, based on studies of red deer (Cervus elaphus). The increase in secretion of testosterone by the testes at puberty stimulates the initial development of the antler pedicles, and the subsequent cycle in the secretion of testosterone dictates the seasonal casting and regeneration of the antlers. High blood concentrations of testosterone in the autumn cause the calcification and death of the antler tissue; and withdrawal of testosterone in the spring, when the testes become fully regressed, allows the old antlers to be cast, and the wound on the surface of the pedicles triggers the regeneration of new antlers.

In the temperate-zone species studied, males are fertile only during the hard antler phase (Lincoln, 1985) and there is significant development of the testes before the rut, e.g. a 6-fold increase in weight in roe deer (Capreolus capreolus) (Bramley, 1970), a 4-5-fold increase in red deer (Lincoln, 1971) and a nearly 3-fold increase in fallow deer (Dama dama) (Chapman \& Chapman, 1970). Associated with this testicular cycle are changes in the weight and activity of the male accessory glands (Lincoln, 1971; Chapman \& Chapman, 1979; Yamauchi et al., 1983). In contrast,

*Author for correspondence. 
little is known about the breeding biology of tropical cervids; generally, reproduction is less seasonal and a post-partum oestrus is more common than in temperate-zone species (Sadleir, 1987).

Whilst there are few data on reproductive cycles of tropical and subtropical cervids in their native habitats, two species have been studied in captive conditions in temperate zones. Chital deer ( Axis axis) in southern England have marked annual cycles in body weight, testicular diameter and testosterone secretion associated with the antler cycle (Loudon \& Curlewis, 1988), but these annual cycles were not synchronized among stags and were not affected by photoperiodic cues. Loudon $\&$ Curlewis (1988) collected motile spermatozoa at all stages of the testis cycle by electroejaculation, but their histological evidence suggested that only limited spermatogenesis occurs at the nadir of the testis cycle. Consequently, collection of motile spermatozoa throughout the year may have reflected storage in the epididymis rather than continued spermatogenesis (Loudon \& Curlewis, 1988). For male Javan rusa deer (Cervus rusa timorensis), held under farming conditions in southern Australia, peak mean plasma testosterone concentrations occurred in May, whereas the major rutting period started at the end of July and extended to October (van Mourik et al., 1986). However, occasional births were recorded well out of the normal birth period.

Reeves' muntjac (Muntiacus reevesi) are native to China, where their range extends from the east coast and south China as far north as Qinghai Province and southern Jiangxi. Eastern Sichuan is probably the western limit, and they are also found on Taiwan (Ohtaishi \& Gao, 1990). This gives the latitudinal range from just inside the Tropic of Cancer to $\sim 36^{\circ} \mathrm{N}$. Feral Reeves' muntjac are now also established throughout much of southern England (Anderson \& Cham, 1988). Adult male muntjac in England have synchronous annual antler cycles, casting occurring in May and June and cleaning of velvet from mid-August to mid-October; the mean antler growing period is 106 days (Chapman \& Chapman, 1982). Female muntjac may attain puberty at 5 months, although first oestrus usually occurs at 8 months of age. Gestation is 210 days and is immediately (i.e. within $24 \mathrm{~h}$ ) followed by a post-partum oestrus; most of the does that do not conceive then have an interbirth period of 234-235 days, suggesting that the next oestrus is 24-25 days later ( $\mathrm{N}$. G. Chapman, unpublished data from captive animals). In Britain, fawns are likely to be born in any month of the year in feral populations and there is no evidence for seasonal peaks in births (Chapman et al., 1984), although, in a captive colony in Japan, birth peaks apparently occurred in May and December (Yoshihara \& Miura, 1984). Little is known about the reproductive cycle of Reeves' muntjac in China, except that births occur throughout the year and the gestation period is believed to be about the same as in England (H. Lu \& H. Sheng, personal communication).

Although female muntjac appear to breed throughout the year, the sexual cycle of male muntjac has not been studied in detail. Chaplin (1973) stated that male muntjac are fertile throughout the year, although no data were presented to support this suggestion. In this paper, we examine the reproductive cycle of adult male muntjac, to determine whether and how they maintain year-round fertility.

\section{Materials and Methods}

Post-mortem material. From 1967 onwards, but mostly from 1980 to 1989,190 adult male muntjac from southern England (latitudes $50^{\circ} 50^{\prime}-52^{\circ} 30^{\prime} \mathrm{N}$ ) were obtained as culled animals or road traffic victims. A male muntjac was considered to be adult after casting its first antlers; these are generally small and lack the coronets present on all subsequent antlers. Most animals were culled in winter and this was also the period of most road accidents; hence monthly sample sizes were not uniform and ranged from 6 (July) to 40 (February). Entire body weights were recorded when possible. The age of animals $<2$ years old was determined by tooth eruption (Chapman et al., 1985). The approximate age of animals with full permanent dentition ( $>2$ years) was estimated by comparing tooth wear with that of captive animals of known age and with a smaller number of tagged free-living animals for which approximate ages were known. Reproductive organs and accessory glands were fixed and stored in 10\% formal saline. Because of damage incurred during collection, particularly in road traffic accidents, it was not always possible to collect every sample from each animal. After dissection, the weights of each testis, caput epididymidis, cauda epididymidis, vas deferens and bulbo-urethral gland were recorded, as were the weights of the paired ampullae and seminal vesicles. Since it was not possible to weigh the prostate tissue independently, the whole pelvic urethra was weighed. 
Histology. Samples from selected animals for each month were dehydrated in ethanol and embedded in paraffin wax. Serial sections were cut at $4 \mu \mathrm{m}$ and stained with Harris's haematoxylin and eosin. Measurements were by a single observer using a calibrated eyepiece from 25 fields of view on each slide. For testis sections, mean tubule diameter, abundance of spermatozoa (scale of 0.5 with increasing abundance) and the presence of spermatogenesis and elongated spermatids were recorded. Sections of the caput epididymidis were cut midway along the length and for the cauda epididymidis between the midpoint and the distal end. For both caput and cauda sections, epithelium height and abundance of spermatozoa (scale 05 with increasing abundance) were recorded. For the ampullae, epithelium height and abundance of spermatozoa according to how many of the alveoli contained spermatozoa (scale 0.4 with increasing abundance) were recorded, as was the height of the epithelium in the seminal vesicles.

Endocrine and castration studies. Blood samples were obtained from individually marked bucks in a captive colony $(n=21)$ and a nearby free-living population $(n=5)$ in north-west Suffolk, UK $\left(52^{\circ} 20^{\prime} \mathrm{N}\right)$. Only samples from animals for which the dates of antler casting and/or cleaning were known were used in the analysis. Samples were collected by jugular venepuncture into $10-\mathrm{ml}$ heparinized syringes. The animals were anaesthetized with an i.m. injection of $1.73 .4 \mathrm{mg}$ xylazine $\mathrm{HCl} / \mathrm{kg}$ (Rompun; Bayer) or an intravenous injection of $10 \mathrm{mg}$ methohexitone sodium $/ \mathrm{kg}$ (Brietal; Elanco) (Cooper et al., 1986). Plasma was stored at $-10^{\circ} \mathrm{C}$ pending analysis. Plasma testosterone concentrations were measured by extraction radioimmunoassay (Corker \& Davidson, 1978). The sensitivity of the assay was $3.5 \mathrm{nmol} / 1$ plasma, and the intra- and interassay coefficients of variation were $<15 \%$. The antiserum used was sheep 505, which has very low cross-reactivity with other steroids (Webb et al., 1985). Two adult captive males were castrated while in hard antler. Three younger males were also castrated when one had small pedicles only, one had its first antlers in velvet and one had just cast its first antlers.

Statistical analysis. MANOVA was used to compare the mean testis, caput epididymidis, cauda epididymidis and vas deferens weight, the mean weight of the bulbo-urethral glands, the paired weights of the ampullae and seminal vesicles and the pelvic urethra weight, for animals in hard antler with those in velvet. When animals either casting or cleaning and those with missing values had been rejected, only 78 cases remained. Hotellings $T^{2}$ test weakly rejected the null hypothesis $(F=2 \cdot 13, P=0 \cdot 045)$. This separation was due to differences in testis weight $(F=7 \cdot 70, P=0 \cdot 007)$, caput epididymidis $(F=11.82, P=0.00 t)$ and cauda epididymidis $(F=10.53, P=0.002)$. None of the other measures was significantly different between the two samples. The mean weights ( \pm s.e.m.) given are for the whole sample and not just for the cases included in the MaNOVA.

\section{Results}

\section{Testicular cycle}

Although the mean testicular weight of bucks in velvet $(7 \cdot 10 \pm 0 \cdot 16 \mathrm{~g}, n=20)$ was significantly lower than that of bucks in hard antler $(9 \cdot 19 \pm 0.32 \mathrm{~g}, n=146)$ (Fig. la), there was no significant corresponding difference in mean tubule diameter (Fig. la), mean sperm abundance or percentage of animals with elongated spermatids (Fig. lb). All stages of spermatogenesis were recorded in each month, including the antler growing period. In 8 of the 115 animals examined histologically, only a few or no elongated spermatids and no spermatozoa were recorded. There was no association between month (January, March, April, May, August, September (2) and December), antler status or age in these animals. Although none was in velvet, one was freshly cast and one was cleaning its antlers.

Mean testicular weight of adult bucks in hard antler was significantly correlated with entire body weight (mean testicular weight $(\mathrm{g})=2.02+0.49$ body mass $(\mathrm{kg}) ; n=102, r=0.434$, $P<0.001)$. However, entire body weight increased only slightly with age and there was no increase in mean testicular weight of adult bucks in hard antler with age (Table 1).

\section{Epididymides}

For the caput epididymidis, the mean weight during the velvet period $(0.51 \pm 0.03 \mathrm{~g}, n=15)$ was significantly lower than for the hard antler phase $(0.64 \pm 0.01 \mathrm{~g}, n=122)$. Similarly, for the cauda epididymidis, the mean weight for bucks in velvet $(0.64 \pm 0.05 \mathrm{~g}, n=16)$ was significantly lower than for bucks in hard antler $(0.94 \pm 0.02 \mathrm{~g}, n=126)$, but, for the vas deferens, the mean weight for bucks in velvet $(0.28 \pm 0.03 \mathrm{~g}, n=15)$ did not differ significantly from that for bucks in hard antler $(0.54 \pm 0.21 \mathrm{~g}, n=120)$ (Fig. 2a). 

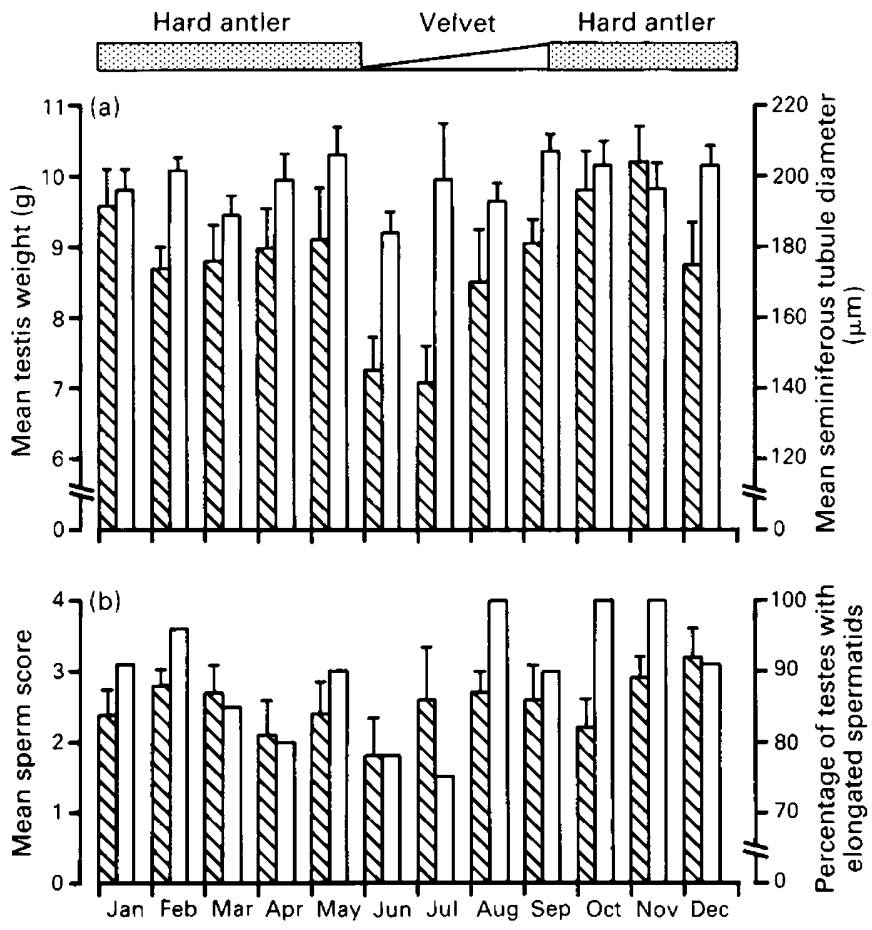

Fig. 1. Annual changes in testis activity in adult muntjac: monthly changes (a) in mean testis weight $(\mathbb{Q})$ and seminiferous tubule diameter $(\square)$; (b) mean sperm abundance score in seminiferous tubules $(\mathbb{\nabla})$ and percentage of testes with elongated spermatids $(\square)$. The mean dates of antler casting and cleaning are based on data from a captive population (Chapman \& Chapman, 1982). Vertical lines indicate s.e.m.

Table 1. Body weights of adult muntjac bucks and testis weights of bucks in hard antler

\begin{tabular}{lcccr}
\hline $\begin{array}{l}\text { Age class } \\
\text { (years) }\end{array}$ & $\begin{array}{c}\text { Body weight } \\
(\mathrm{kg})\end{array}$ & $n$ & $\begin{array}{c}\text { Mean testis weight }(\mathrm{g}) \\
\text { of bucks in hard antler }\end{array}$ & $n$ \\
\hline$<2$ & $13 \cdot 2 \pm 0.4$ & 17 & $8 \cdot 72 \pm 0.58$ & 12 \\
$2-3$ & $14.0 \pm 0.4$ & 10 & $9 \cdot 39 \pm 0.53$ & 9 \\
$3-5$ & $14.3 \pm 0.4$ & 15 & $9 \cdot 24 \pm 0.47$ & 28 \\
$>5$ & $14.6 \pm 0.3$ & 22 & $8.88 \pm 0.26$ & 24 \\
\hline
\end{tabular}

Data are means \pm s.e.m.

The sections of the caput epididymidis exhibited two distinct zones, of which one, the initial segment, had a tall but somewhat irregular epithelium and the lumen contained few spermatozoa. The other zone, part of the middle segment (Glover \& Nicander, 1971), always contained spermatozoa. This segment had a tall, pseudostratified epithelium with stereocilia. The height of this epithelium, excluding the stereocilia, was measured. The section of the cauda epididymidis showed two distinct zones. Measurements were made of the zone of larger tubules, many of which were rounded or kidney-shaped in cross-section and were almost always packed with spermatozoa. The tubule epithelium was cuboidal and much thinner than that lining the caput epididymidis. There was no seasonal variation in the mean epithelium height for either caput or cauda epididymidis 


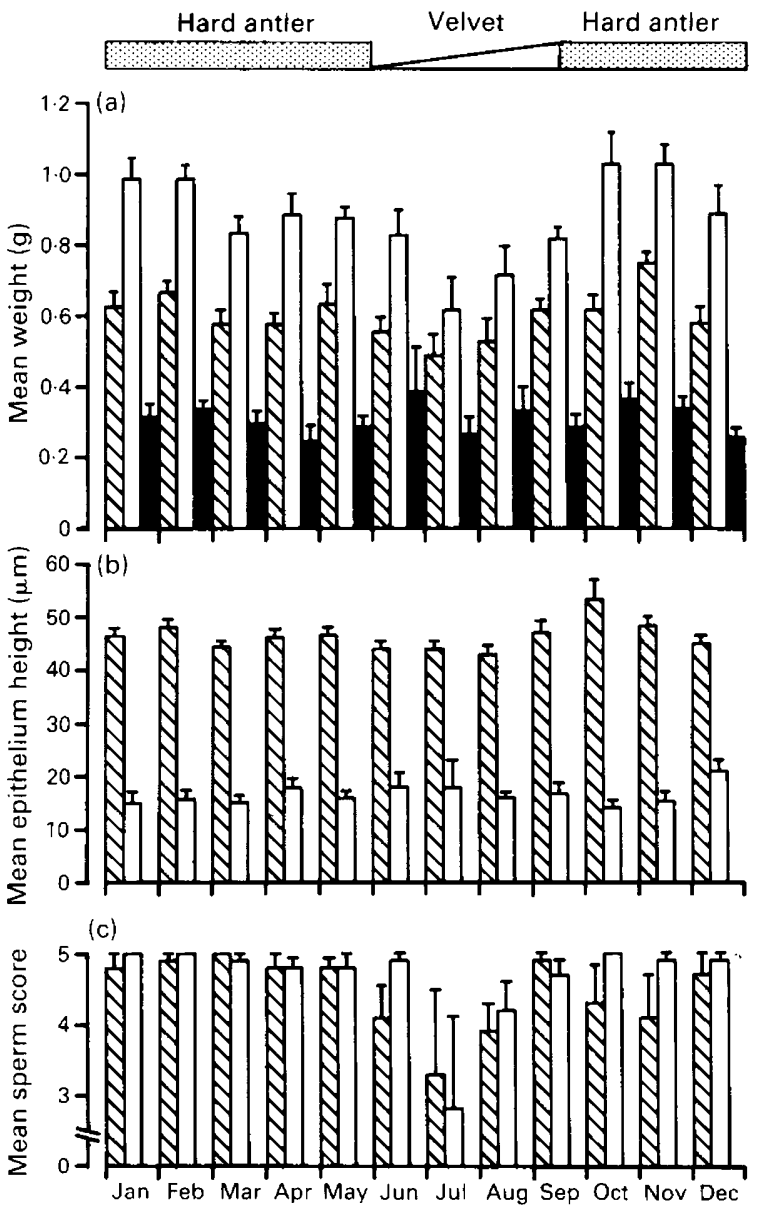

Fig. 2. Annual changes in epididymidis and vas deferens activity in adult muntjac: monthly changes in (a) mean weight of caput epididymidis $(\$)$, cauda epididymidis $(\square)$ and vas deferens ( $\boldsymbol{a})$; (b) mean epithelium height and (c) mean sperm abundance score in caput epididymidis $(\mathbb{S})$ and cauda epididymidis $(\square)$. The mean dates of antler casting and cleaning are based on data from a captive population (Chapman \& Chapman, 1982). Vertical lines indicate s.e.m.

(Fig. 2b), although there was a reduction in the mean sperm abundance in both caput and cauda epididymides during the period in velvet (Fig. 2c).

\section{Accessory glands}

In common with other cervids that have been examined, Reeves' muntjac had accessory glands comprising ampullae, seminal vesicles and prostate glands, but in addition there was a large pair of bulbo-urethral glands (Fig. 3). These have been recorded in Indian muntjac (Muntiacus muntjak) and reindeer (Rangifer tarandus) by Oudemans (1892) and in black-tailed deer (Odocoileus hemionus columbianus) by West \& Nordan (1976). They were described in Reeves' muntjac under the name of paraurethral glands by Dansie \& Williams (1973).

For the ampullae, the weight for bucks in velvet $(0.58 \pm 0.04 \mathrm{~g}, n=15)$ was not significantly lower than for bucks in hard antler $(0.70 \pm 0.02 \mathrm{~g}, n=105)$, as for the bulbo-urethral glands $(1 \cdot 28 \pm 0.12 \mathrm{~g}, n=14$, and $1.23 \pm 0.04 \mathrm{~g}, n=90)$ (Fig. $4 \mathrm{a}$ ), seminal vesicles $(2 \cdot 50 \pm 0.17 \mathrm{~g}$, $n=16$, and $3.12 \pm 0.13 \mathrm{~g}, n=104)$ and the pelvic urethra $(2.02 \pm 0.07 \mathrm{~g}, n=16$, and 


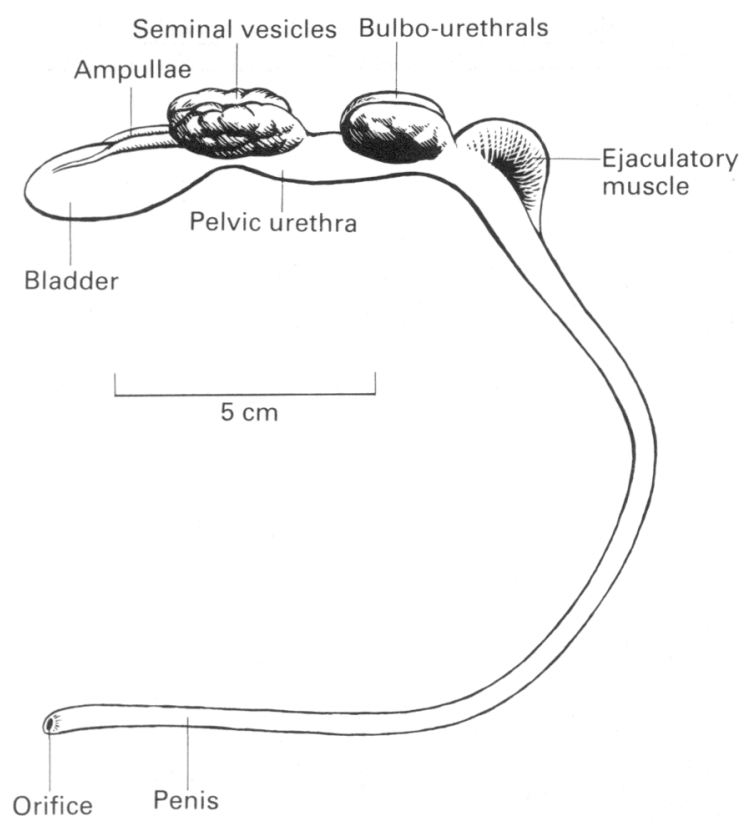

Fig. 3. Accessory reproductive glands of adult male muntjac, showing in particular the large bulbo-urethral glands in this species.

$2 \cdot 32 \pm 0.12 \mathrm{~g}, n=92$ ) (Fig. 4b). There was no significant monthly variation in the epithelium height of the ampullae and seminal vesicles, or in sperm abundance in the ampullae (Fig. 4c).

\section{Plasma testosterone concentrations}

Mean plasma testosterone concentrations were $11.4 \pm 2.0 \mathrm{nmol} / 1$ for bucks in velvet or $<30$ days before casting $(n=16)$ and $16.1 \pm 2.4 \mathrm{nmol} / 1$ for bucks in hard antler $>30$ days before casting $(n=10)(t=1 \cdot 50, P>0 \cdot 1)$.

\section{Effects of castration}

Of the two adult bucks, one was castrated in October and its antlers were cast after 25 and 29 days. The other buck was castrated in January and cast after 58 and 88 days. All castings were outside the normal season. New antler growth occurred in both animals, but the velvet was not cleaned. Pedicle development was arrested in the young buck castrated before puberty. In the young male castrated while its antlers were in velvet, no subsequent cleaning occurred. The third young male, castrated just after it cast its first antlers, grew a second set of antlers, but no subsequent cleaning occurred. With the exception of the prepubertal buck, all castrated bucks grew velvet antlers. One animal was observed for 8 , one for 12 and two for 14 months, but none showed signs of developing perruque heads.

\section{Discussion}

In cervids, the antler cycle is associated with pronounced changes in testicular size and androgen secretion. Seasonal changes in the activity of accessory glands, many scent glands and other secondary sexual characteristics, such as increases in neck circumference and growth of the neck mane, have been described for some temperate species of deer (e.g. Lincoln, 1971; Schnare \& 

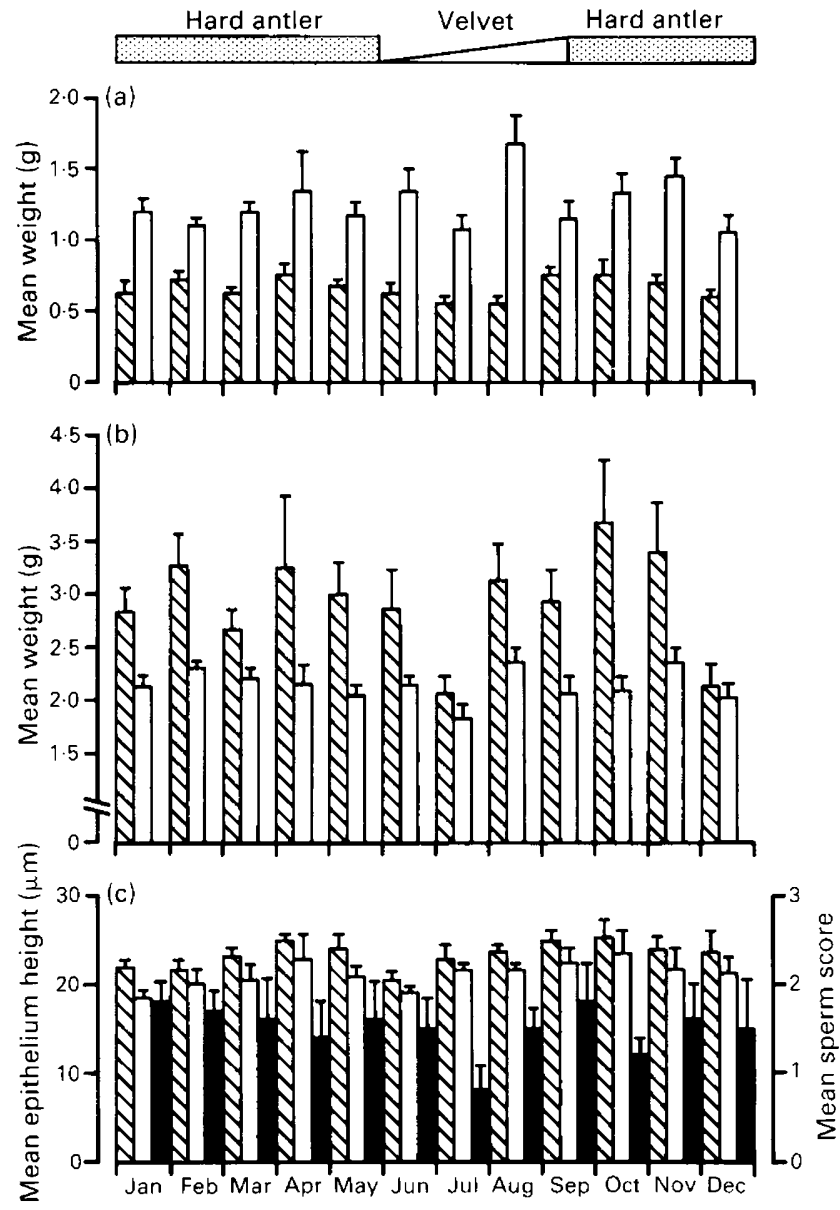

Fig. 4. Annual changes in accessory glands in adult muntjac: monthly changes in (a) mean weight of ampullae $(\mathbb{\mathbb { N }})$ and bulbo-urethral glands $(\square)$; (b) mean weight of seminal vesicles $(\mathbb{\mathbb { N }})$ and of pelvic urethra $(\square)$; and (c) mean epithelium height of ampullac $(\mathbb{Q})$ and seminal vesicles $(1)$, and mean sperm abundance score in ampullae $(\boldsymbol{Q})$. The mean dates of antler casting and cleaning are based on data from a captive population (Chapman \& Chapman, 1982). Vertical lines indicate s.c.m.

Fischer, 1987). In a review of reproduction in cervids, Lincoln (1985) noted that there were considerable gaps in knowledge of basic details for many species, and that information on the breeding physiology of tropical species was particularly lacking. One of the only detailed studies of a tropical cervid species involved a captive herd of chital deer held in temperate Europe (Loudon \& Curlewis, 1988). In this species, although there was a distinct 12-month cycle of antler growth, testis size and neck circumference for each stag, there was little synchrony between individuals. Loudon \& Curlewis (1988) concluded that, in contrast to temperate-zone species, the photoperiodic-pineal link to the reproductive axis in chital deer may be absent or only able to entrain the reproductive system weakly and that long-term cyclic changes in testicular activity may occur in the absence of photoperiodic entrainment.

In Reeves' muntjac, the antler cycle exhibits a high degree of synchrony between adult bucks (Chapman \& Chapman, 1982), although there is no marked seasonal variation in body size, neck circumference (N. G. Chapman, unpublished data) or testis size (present study). Although there is 
a $23 \%$ reduction in mean testis size of bucks in velvet, Lincoln (1985) suggested that in cervids a decline in testis weight of $>75 \%$ of the seasonal maximum is usually associated with complete arrest in spermatogenesis. In muntjac, the small reduction in testis size was not associated with a reduction in mean diameter of seminiferous tubules, mean sperm abundance, or percentage of animals with elongated spermatids or undergoing spermatogenesis. Furthermore, there was no evidence of a seasonal change in epithelium height in the caput or cauda epididymides, although there was a small decline in mean sperm abundance during the period of velvet antlers. It would appear, therefore, that the epididymis does not have an increased capacity for storage of spermatozoa during antler growth. Similarly, there is no evidence for any seasonal changes in activity of, or spermatozoa storage by, the ampullae.

Based on a sample of 153 animals for which the month of birth or conception could be calculated, Chapman et al. (1984) found no evidence of seasonal variation in birth or conception dates. We enlarged this sample with a further 102 animals, but can still find no evidence of seasonal variation. Furthermore, observations of behaviour in the free-living population in Suffolk indicate little seasonal variation in social behaviour and buck aggression, unlike most seasonally breeding cervids. Specific observations on the captive colony showed that, 5 times during May-August, the only males with access to females 210 days before parturition were all in velvet. On 4 of these occasions, the males were about half-way through the antler growth period; in one instance the male was a subadult growing its first antlers, while the others were adult bucks. The fifth was a buck at a later stage of antler development, only 3 weeks away from cleaning. Dansie (1983) gives two examples of captive fawns being sired by bucks in velvet, and Yoshihara \& Miura (1984), observing a captive colony in Japan, estimated that $\sim 30 \%$ of 172 fawns were sired by bucks in velvet.

In temperate-zone deer species, antler casting is associated with declining testosterone secretion, and cleaning of the velvet with increasing concentrations of testosterone secretion (Lincoln, 1984). The role of the testis, and hence probably testosterone, in inducing the hard antler state in muntjac was confirmed by castrating 5 captive muntjac at various ages and stages of the antler cycle, albeit that the endocrine data suggest that the cycle of testosterone secretion is less well defined than in most other deer species studied. The testosterone data presented here should be confirmed by moredetailed studies on serial samples from captive animals, since samples collected from wild-caught, and hence stressed, animals are difficult to interpret. Furthermore, testosterone is secreted in a highly pulsatile manner and one of the anaesthetics used (xylazine) is known to affect pituitary (and hence testicular) secretory function.

This study has shown that year-round fertility in adult muntjac bucks is achieved by year-round spermatogenesis and not by increased sperm storage. This situation has not been recorded in any other cervid and raises a number of important questions. In particular, why do adult muntjac have a well-defined and synchronous antler cycle when there is no peak in sexual activity? Also, what drives the antler cycle of muntjac bucks? Testosterone is likely to be only one of a number of hormones involved in the process. Muntjac appear to be an ideal model species for further studies on the hormonal control of the antler cycle.

We thank the many people who have supplied the post-mortem material, especially T. Bailey, T. K. Bradbury, S. Carter, the late D. I. Chapman, K. Cresswell, A. Hoon, J. Radmall, A. Reeman, K. Siford and R. Whitta; Diane Blakeley and Kathie and Mick Claydon for considerable help in collecting and analysing the observational data on the free-living deer; Dr G. A. Lincoln for the testosterone assays; Mr G. Troughton for drawing Fig. 3; Dr A. B. Bubenik, Dr G. A. Bubenik, Dr G. A. Lincoln, Dr A. S. I. Loudon, Professor P. A. Racey and two referees for helpful comments on drafts of the manuscript; and Mavis Rogers and Debra Young for typing the manuscript. N. G. Chapman is indebted to the Research Fund of the University of London for the provision of apparatus, and Stephen Harris thanks the British Ecological Society for a Small Ecological Project Grant to study the behaviour of free-living muntjac. 


\section{References}

Anderson, D. \& Cham, S.A. (1988) Muntjac deer (Muntiacus reevesi)-the early years. Beds. Nat. 42, 14-18.

Bramley, P.S. (1970) Territoriality and reproductive bchaviour of roe deer. J. Reprod. Fert., Suppl. 11, $43 \cdots 70$.

Bubenik, G.A. (1986) Regulation of seasonal endocrine rhythms in male boreal cervids. In Endocrine Regulations as Adaptive Mechanisms to the Environment, pp. 461-472. Eds 1. Assenmacher \& J. Boissin. Centre National de la Recherche Scientifique, Paris.

Chaplin, R.E. (1973) Antler cycle in muntjac. Deer 3, 51. Chapman, D.I. \& Chapman, N.G. (1970) Preliminary observations on the reproductive cycle of male fallow deer (Dama dama L.). J. Reprod. Fert. 21, 1-8.

Chapman, D.I. \& Chapman, N.G. (1982) The antler cycle of aduit Reeves' muntjac. Acta theriol. 27, $107-114$.

Chapman, D.I., Chapman, N.G. \& Colles, C.M. (1985) Tooth eruption in Reeves' muntjac (Muntiacus reevesi) and its use as a method of age estimation (Mammalia: Cervidae). J. Zool., Lond. (A) 205, 205-221.

Chapman, D.I., Chapman, N.G. \& Dansie, O. (1984) The periods of conception and parturition in feral Reeves' muntjac (Muntiacus reevesi) in southern England, based upon age of juvenile animals. J. Zool., Lond. 204, 575-578.

Chapman, N.G. \& Chapman, D.I. (1979) Seasonal changes in the male accessory glands of reproduction in adult fallow deer (Dama dama). J. Zool., Lond. $189,259-273$.

Cooper, J.E., Harris, S., Forbes, A., Chapman, N.G. \& Chapman, D.I. (1986) A comparison of xylazine and methohexitone for the chemical immobilization of Reeves' muntjac (Muntiacus reevesi). Br. vet. J. 142 , 350-357.

Corker, C.S. \& Davidson, D.W. (1978) A radioimmunoassay for testosterone in various biological fluids without chromatography. J. Steroid Biochem. 9, 373-374.

Dansie, O. (1983) Muntjac. British Deer Society. London.

Dansie, O. \& Williams, J. (1973) Paraurethral glands in Reeves muntjac deer, Muntiacus reevesii. J. Zool., Lond. 171, 469471.

Glover, T.D. \& Nicander, L. (1971) Some aspects of structure and function in the mammalian epididymis. J. Reprod. Fert., Suppl. 13, 39-50.

Lincoln, G.A. (1971) The seasonal reproductive changes in the red deer stag (Cervus elaphus). J. Zool., Lond. $163,105-123$
Lincoln, G.A. (1984) Antlers and their regeneration-a study using hummels, hinds and haviers. Proc. Roy. Soc. Edinb. 82B, 243-259.

Lincoln, G.A. (1985) Seasonal breeding in deer. Bull. Roy. Soc. N. Z. 22, $165 \cdots 179$.

Loudon, A.S.I. \& Curlewis, J.D. (1988) Cycles of antler and testicular growth in an aseasonal tropical deer (Axis axis). J. Reprod. Fert. 83, 729-738.

Ohtaishi, N. \& Gao, Y. (1990) A review of the distribution of all species of deer (Tragulidae, Moschidae and Cervidae) in China. Mammal Rev. 20, 125-144.

Oudemans, J.T. (1892) Die Accessorishchen Geschlechtsdrüssen der Säugethiere. Haarlem.

Sadleir, R.M.F.S. (1987) Reproduction of female cervids. In Biology and Management of the Cervidae, pp. 123 144. Ed. C. M. Wemmer. Smithsonian Institution Press, Washington.

Schnare, H. \& Fischer, K. (1987) Secondary sex characteristics and connected physiological values in male fallow deer (Dama dama L.) and their relationship to changes of the annual photoperiod: doubling the frequency. J. exp. Zool. 244, 463-471.

van Mourik, S., Stelmasiak, T. \& Outch, K.H. (1986) Seasonal variation in plasma testosterone, luteinizing hormone concentrations and $\mathrm{LH}-\mathrm{RH}$ responsiveness in mature male rusa deer (Cervus rusa timorensis). Comp. Biochem. Physiol. 83A, 347-351.

Webb, R., Baxter, G., McBride, D., Nordblom, G.D. \& Shaw, M.P.K. (1985) The measurement of testosterone and oestradiol- $17 \beta$ using iodinated tracers and incorporating an affinity chromatography extraction procedure. J. Steroid Biochem. 23, 1043-1051.

West, N.O. \& Nordan, H.C. (1976) Hormonal regulation of reproduction and the antler cycle in the male Columbian black-tailed deer (Odocoileus hemionus columbianus). Part 1. Seasonal changes in the histology of the reproductive organs, serum testosterone, sperm production, and the antler cycle. Can. J. Zool. 54, 1617-1636.

Yamauchi, S., Ukai, Y., Yaguchi, M.\& Nishitani, Y. (1983) Study on male accessory sex glands in Japanese deer, Cervus nippon (Nara Park), particularly on the seasonal changes. Jap. J. Anim. Reprod. 29, 32-38.

Yoshihara, M. \& Miura, S. (1984) Birth records of captive Reeve's muntjacs. J. Mammal. Soc. Japan 10, 35-36.

Zuckerman, S. (1953) The breeding seasons of mammals in captivity. Proc. zool. Soc. Lond. 122, 827-950.

Received 8 August 1990 